\title{
The Cosmological and Ethical Aspects of Musical Modus: Ontological Approach VS the Semiotic Approach
}

\author{
Anastasia Medova \\ Department of Philosophy and Social Science \\ Reshetnev Siberian State University of Science and Technology \\ Krasnoyarsk, Russia \\ E-mail: amedova@list.ru
}

\begin{abstract}
The paper dedicates cosmological and ethical aspects of the musical modus. In the musicology, the notion of modus is referred to the certain modes and rhythms which have the sense of spiritual states and cosmic phenomena in some cultural traditions (ancient Greek, medieval Indian, Chinese, Russian). The study aims at the comprehension of music modus as the point of coincidence of harmonic, ethic, and cosmological dimensions intrinsic to music. The author interests in the ontological essence of the unity of natural or ethical phenomena and music modus considering the examples of the medieval Chinese system of tones "lyuj", antique moditetrachords, Indian ragas, and Russian Orthodox modes. The author puts forward the number of arguments against the semiotics approach to this unity. It is not a conventional ("by agreement") matching of the musical modi and cosmological or ethical phenomena. The author argues the musical modi should be considered more effective as elements of a musical ontology in the context of the multidimensional syncretic modal ontology.
\end{abstract}

Keywords-musical modus; musical ethos; syncretism; musical ontology; ancient diatonic modes; raga; svara

\section{INTRODUCTION}

Research of musical modus is of interest for musicologists, culturologists, and philosophers due to a versatility of the phenomenon. Music theory describes the rhythmic structures, modes, harmonic systems, intonational archetypes, melodic models as modi. But the music modiare spiritual conditions, cosmic phenomena and social relations as well. The notion of musical modus is referred to musical form, content and world outlook at the same time. The fact arouses scientific interest and attempts of various treatments of musical modality.

On the one hand, modus is the fundamental type of musical thinking, which was supplanted by functional tonality thinking in the XVII century and claimed about itself in music of the XX century again. On the other hand, modus is the category that signified the unity of music, human spirit, and cosmos. In this case, modus is not a notion of music theory but a notion of art-ontology.
We consider the basis of global unity which stands behind the phenomenon of music modus. The study aims to the comprehension of music modus as the point of coincidence of harmonic, ethic, and cosmological dimensions intrinsic to music. To reach this goal, we will consider the main approaches to modality in theory of rhythm, mode, and musical content. Then we will describe some historical examples of cosmological and ethic interpretation of musical modus. It allows us to put forward the version of modal oneness applied to the studied phenomenon. The proposed version is based on the ontology of syncretism and analyses of the specificity music semantic reference. It also takes into account the data of psychophysiological researches.

\section{THEORETICAL BACKGROUND TO THE RESEARCH}

Musical modus is traditionally considered in two dimensions: in the scopes of musical language theory and musical content. From the theoretical point of view, the notion of musical modality is understood in two ways: in the concrete historical sense and in the universal one. In the historical sense, the notions "modus" and "modality" signify the peculiarities of the music created from the ancient period to the Renaissance. In the second sense, it is a type of harmonic and rhythmic thinking which characterizes specific ways of setting a reference tone and music time division.

Primarily, the ancient modi are known as modes, i.e. range of tones. But the melodic intonational comprehension of modus preceded this point of view [1]. In the Middle Ages, modus is thought to be combinations of some certain melodic formulas applied at church singing [2]. The famous source of the Renaissance giving the information concerning modus as a form of mode is the treatise by Gioseffo Zarlino "The ascertainment of harmony" (1558). Here, Zarlino mentioned seven ranges of tones calling them "modi".

The rhythmic patterns of medieval music applied mainly in the XII-XIII centuries are attributed as rhythmic modi. They are the common six triple-time models analogous to the poetic meters - I (trochee), II (iamb), III (dactyl), IV (anapest), V (spondee), and VI (tribrach). 
The contemporary composition considers modality as a method to create musical form on the basis of various natural and synthetic modes as well as freely selected melodic and rhythmic modi.

There are very few studies dedicated to comparative analysis of modal and non-modal (i.e. tonal) music systems $[3,4]$.The modal harmony has a number of principal differences from tonality. It does not demand temperament, for this reason, it allows to use non-thirded structure of chords. The entity of harmonic modality is an absence of such functional relations between tones which would be set in advance, a priori. Here is not some unified reference tone, the same tones of a mode can be stable, or not stable, or neutral upon the function. Modal rhythm does not have a predetermined system based on the mathematical division of musical time to equal parts. Rhythmic modi are catchy models not divided into separate elements.

The theory of modus as musical content was elaborated in a considerable degree; it is the second scope of modal research in music. The fundamental studies in this direction were carried out by Russian musicologist E. Nazajkinskij in his work "The Logic of musical composition". A musical modus is defined here as a holistic art-mediated condition specific in its content and embodied in music in diverse forms by different means and ways.

In this conception, modus is associated with the category of condition. According to Nazajkinskij, musical modus can be contemplative, active, calm, intense, purposeful, concentrated or diffusive. Music pieces can be written in an emotional, logic or pictorial key (modus). Understood in such a way, modus can be turned to consciousness either by a facet of immediate feelings, or a facet of mood, or a peculiarity of thinking process. Hence, modus is one of the possible facets of an artistic wholeness. On the level of content, musical modi are art-mediated conditions of objective and subjective being.

\section{COSMOLOGICAL INTERPRETATION OF THE MODUS}

The musical modality is mostly studied in the levels of harmony, rhythm, and music content. Nevertheless, there are other levels of musical modality significant for the point of view of artistic ontology. It is the cosmological dimension of modus. A demonstrative example of such understanding is the medieval Chinese system of 12 normative sounds "lyuj" with fixed pitch. The pentatonic modes were rebuilt every month according to each of them ${ }^{1}$. Thus, there were the modes for all 12 months. Music instruments retuned every month such a way that first reference tone of a mode coincided with one of lyuj. The medieval Chinese writing did not fix a certain pitch of sound. In view of this, we can assume lyui was rather a speculative phenomenon than actually musical tuning. But the system of lyui had high world outlook value. This practice of normative modes explained Confucius's statement that playing an improper music is a threat for the state [6]. In the described ontology, a

\footnotetext{
The mode typical for Chinese folklore which composed by means of five tones without semitones.
}

state is a facet of the universe as well as music. The thought of Plato tells about such unity: "For they must beware of change to a strange form of music, taking it to be a danger to the whole. For never are the ways of music moved without the greatest political laws being moved" (Rep. 424 c) [7].

The cosmologic interpretation of music modus took place in the antique aesthetic. Aristides Quintilianus characterizes modi-tetrachords (scales composed by means of four tones) in the following way: "We had disclosed that the five main elements match such [tetrachords]: [tetrachord] of low - the Earth as the lowest, [tetrachord] of middle - the Water as the nearest to the Earth, [tetrachord] of connected - the Air, for there it came descending in sea depths and burrows of the Earth. The Fire matches [tetrachord] of divisible for there, moving down is undesirable for it nature while transit upward is native for it, [tetrachord] of upper matches the Ether that has to concern an edge of the world" [8].

An ancient Indian genre and melodic model "raga" also was a modus in the ontological sense. In the oldest musical treatise, "Gitalankara" by Bharata, there was deeply elaborated system of modes (varnes). The basic group consists of the 12 male modes, from which are derived the 12 female modes, and also the 12 modes as their children. Each mode, besides in all things, is related to a certain color; "varna" literally means "color". Svaras, that also composed the modes, were endowed with their own color, as well. The ancient Indians assumed that sound and color had one common nature based on the vibration [9].

Performing each raga was bound to a concrete part of day divided into eight three-hours parts ("pahar"). Ragas were also distinguished according to the seasons. W. Kaufmann gives the table of allocation of the Indian modes corresponding to their tones during the day [10]. According to Kaufmann, the interval from 7 to 10 a.m. is matched with kal'yan and bilaval ragas (modes), the interval from 10 a.m. to 1 p.m. presupposes a music played in bhajravi, todi, asavari, and kafi modes, while todi and kafionly mode sare only for the interval from 1 to 4 p.m.

The most scientific interest lies in the ontological essence of the unity of music modus and natural phenomenon. Was it only conventional and settled by tradition or had it any other basis? This question is difficult to be explored and can be explained by the following inquiry of modias ethoses, i.e. states of spirit. Ethoses as psychological phenomena and the second dimension of musical modiare are available for introspection and psychological analysis. This quality of ethoses grants the possibility for study the principles of this syncretic modal unity.

\section{Modus as Ethos: THE CORRELATION OF MUSICAL AND PSYCHOLOGICAL MODI}

The earliest examples of musical modus-ethos took place in the ancient Indian culture. There was thoroughly elaborated the doctrine called "nava rasa"; the first mention of rasa can be found in the Atharva Veda and Rigveda. According to the Indian aesthetics, one of the nine rasas (love, sadness, joy, anger, heroism, fear, wonder, disgust, serenity) was to constitute an emotional image of a piece of 
art [11]. The rasas were set for all modes and tones. We cannot fail to notice that the seras as are relevant to the basic emotional modalities being studied in the contemporary psychology. Many psychologists attribute fear, contempt, anguish, guilt, interest, joy, shame, surprise, dismay, desire, aversion, courage, dejection, despair, hate, hope, sadness to basic emotions [12].

Similar comprehension of music ethos exists in a European culture. The difference is that the European and Russian traditions ascribe ethical features to modes only, while the Indian tradition endows separate tones (svaras) with an ethical content.

The doctrine of music ethos is associated with the Athenian thinker Damon, who believed that different rhythms and melodies have their own impact on a human soul [13].Damon contributed to the European culture by "paideia" as a music virtue, an idea that "Beauty teaches good". The cause of this impact is assumed to bethe interval pitches of tetrachords, namely the positions of semitone. The diatonic descending tetrachords comprises one semitone and three tones. The Dorian tetrachord has a semitone situated between the third and the fourth tones, the Phrygian tetrachord has a semitone between the second and the third tones, the Ionian one - between the first and the second tones. The Dorian tetrachord embodied masculine features and courage, the Phrygian one - peaceful reasonableness and restraint, the Ionian one - will-less extasy and femininity [14].

The Russian Orthodox music tradition is based on the eight-modes system (oktōēchos) having been used for the composition of religious chant in Byzantine, Syriac, Armenian, Georgian, Latin, and Slavic churches since the Middle Ages. The Russian medieval oktōechos implied a musical ethos like that one of the ancient tetrachords. Each of the eight modes was virtually sets of melodic formulas with strictly established semantics. The treatise "The Historical data on the Greek-Russian church" of 1831 characterized the modes of the oktōēchos in a following way:

- $\quad$ simple and majestic;

- gentle, sweet, compassionate;

- smooth, grave, calm but hard, masculine, peaceful;

- fast, jubilate, delightful, arousing joy;

- languid, despondent but joyful, sometimes solemn at the same time;

- the saddest, able to lead the soul to repent of sins but extremely fascinating at the same time;

- heavy, important, brutal, arousing courage;

- striking, sad, as though lamentable, expressing the deep sorrow of the soul [15].

The melodic models of the oktōēchos modi were uniform; they remain as they are in our time too. Their intonational difference is minimal because the orthodox canon demands a unity and typification of music. Otherwise, the special religious condition of spirit can be lost. Nevertheless, we should notice the fact of the principal ethic differences of the oktōēchos modi, they are also not homogeneous from the ethos point of view within themselves.

\section{MOdus OF SHRUti: AgAinst THE THEORY OF REFERENCE}

The fundamental basis of all musical modi is an objectification of some state or phenomenon in music [16]. From the point of music semantics, the elements of music language and whole music phrases have referents beyond music. Tonalities, intervals, motives correspond to objects like signifier corresponds to designatum. According to this position, music signs are a picture of emotions and conditions. For example, a descending motive from the two nearest sounds with stress on the first sound (so-called lamento) represents nuances of complaint. Hence, we can assert music signs like psychical conditions which they signify although the likeness is not spatial or visual.

However, this approach is not resultative for the investigation of the cosmological and ethics dimensions of the music modus described above. Modi, whether they are modes or rhythms, are not signs of their objects, for examples a part of day or a typical condition of spirit. Owing to it, they are not connected with their objects by convention or likeness. Let us illustrate our claim on the example of svara.

Svara is a tone of Indian mode of raga (that is equal to modus). The main quality of svara is its ability to induce a certain emotion or condition besides some musical context. A kind of aroused emotion depends on which of the shrutis gravitates to this svara.

Shruti is the notion of Indian music theory. If svara is an analogy to a tone of European mode, shrutis compose a svara. Shrutis are the result of more subtle division of a music scale than division by semitones or quarter of tones. If we adhere to understanding the shruti as a way of tuning or music pitch scale, we may come across a contradiction. For instance, in the Sarangadeva's treatise Sangita-Ratnakara (literally "Ocean of Music and Dance") of XIII century shrutis are divided into searing, broad, pitiful, tender, and neutral. So, svarasadja includes four shrutis - broad, tender, searing, and neutral; svararșabha includes pitiful, tender, and neutral shrutis; svaragandhara includes searing and broad shrutis.

How can it be possible if only the pitch of separate sound beyond any mode, rhythm, timbre is not able to arouse an emotion for people today? Moreover, shrutis are the tiny intervals from one-third to one-eighth of tone, in fact, each of them is not distinguishable by ear. Rather we will agree shrutis are just the way of variation and fluctuation of a pitch of tones during a performance on the non-tempered instruments.

Nonetheless, the emotional exposure of each sound was thoroughly studied in the Indian aesthetics. Subsequently, it led to the association of every tone with certain feelings. Modes (ragas) which were composed of the nearest sounds in their emotional significations had to evoke a concrete rasa 
(literally "taste of emotion") in the listeners. Thus, we should agree with Rao and van der Meer concerning the interpretation of shruti. Shruti is the psycho-emotional intonation of a sound which is identical to a cloud of nuances of tones which surrounds it [17]. In this case, it is not a theoretical notion but a manifestation of modal wholeness: it is a unity of consciousness and musical continuum. Interpretation of shruti as a nominal sign of a condition of spirit together with the theory of reference is not adequate in the context of the doctrine of rasa.

\section{DISCUSSION}

We come to the question: how musical mode can be ethos or a cosmological phenomenon? For a contemporary listener, every mode has quite a convention and generalized contents. A mode is an abstract system of functional relations between sounds. Only a concrete melody created in such a mode conveys specific images by helping the rest elements of the musical language (rhythm, harmony, timbre, texture). How can one explain why the modal musical thinking identifies modes and tetrachords with concrete conditions, objects, ideas?

Our version is this: the Russian modes of oktōēchos, ancient Greece tetrachords, Indian ragas and svaras are not incentives of feelings or icons of emotions and objects. Our version is justified by the fact that the musical ethoses include such mental states as burning (searing svara), fascination, reasonableness, will-less extasy, and others. Expressing this ethoses by means of instrumental music without words is very problematic, since the ethoses are multifaceted and have intellectual and cultural aspects - they are not pure psychological phenomena. It is hard to imagine that some gamma or mode might have such complicated content.

The second argument against the understanding of musical modias expressing or incentive of a state of soul is the thesis about direct psychophysiological exposure of a music. Words or symbols of the most of languages play the role of mediators between a signified object and its presentation in consciousness. Musical language does not have such mediation element. Intonations, chords, melodic phrases are not a conventional sign of objects, but objects per se which perceived directly. Owing to it, the music language does not need translation. People do not have to be musically educated to perceive the completeness of music content. It is notable that historical and cultural context influence on perception of musical signs (i.e. intonation complexes) only to a small extent in opposite case the music of past centuries would not be something meaningful for us and would not have such value that we endow it today.

In the light of this approach, there appears an important fact that the subjective experiences of timbres, rhythms, acoustic, and modes relations are similar for most of the people. If there were no such common interpretational invariants, music could not claim its universal significance. Thus, we assume people of the past centuries, when they listened to some modus (mode or raga), immersed themselves in a condition relevant to a certain ethos or rasa.
Hence, it is reasonable to expect the contemporary people also must perceive the modal ethoses listening to music in the same modi.

The hypothesis was checked by Brazil psychophysiologists D. Ramos, J.L.O. Bueno, and E. Bigand [18]. They fixed the emotional impact of the melodies in the diatonic Greek musical modes (Ionian, Dorian, Phrygian, Lydian, Mixolydian, Aeolian, and Locrian) on 48 listeners in the age from 17 to 25 year. Participants in the experiment listened to the one-voices melodies in these modes which sounded in three different tempos: Andantino (metronome 72 $\mathrm{bpm})$, Allegretto (114 bpm), Presto (184 bpm). The melodies needed to be correlated with four states of a soul: happiness, sadness, fear/anger, serenity.

It would naturally be expected, the dominant features of emotional valency of the melodies should have been the positions of the $3 \mathrm{rd}$ and the 6 th tone of the mode relatively the reference tone. Minor 3rd and minor 6th tone are the attributes of minor keys. They make modes sad while major $3 \mathrm{rd}$ and 6th tones make modes happy or serene. However, these natural assumptions were not confirmed experimentally. The results point out only at the fact with increasing the tempo emotional reactions get more intensive or change their valency from positive to negative. For instance, the most listeners perceived the excerpts in the Mixolydian mode as sad or serene when they sounded in tempo Andantino, the same melodies in tempo Allegretto as serene, and in tempo Presto as the happy one [19].

Indicative, feeling of sad replaces a happiness or serenity by increasing the tempo in the most feck of the valuation. This tendency was revealed for all modes except Phrygian and Locrian. In this case, a sad turned into a fear/anger with increasing the tempo. Thus, it can be argued only extremely generalized effect of the interval scale of diatonic modes on a listener's psycho-emotional sphere. Only Locrian mode with low 2nd tone, minor 3rd, and tritone between $1 \mathrm{st}$ and 5 th tones has univocal negative valency. As concerning the rest modi, the rhythm and tempo of melodies make a contribution in the perceiving of their artistic image not in the least bit than the interval scale of the modes. We can conclude, modal gravities per se does not have a stable univocal phsychoemotional impact on contemporary people. And there is no reasonable base to assume people of the Ancient world and Middle Ages were feel exposed such stable univocal phsycho-emotional impact.

\section{CONCLUSION}

Musical modus is not exclusively theoretical category. On the opposite, a phenomenon of modus is notable owing to its realization in the spaces of music grammar, music content, and on the ethic and cosmological levels at the same time. We wonder whether a mode or its separate tone (svara) understood as a modus acquire the status of a period of the annual or daily cycle, element or spiritual state. The analysis of the modi-ethoses convinced us that new dimensions of modi-modes are not the results of a phsycho-emotional respond of people on the sounding of those modes. There is not also any similarity between intonations of modes and 
mental states of people as though modi "imitated" rapture, femininity, courage etc. At the same time, the modal relation cannot be understood as nominal and conventional one, in view of the inexplicability of this convention if only it not mystic or ritual. The preconditions of the modal unity are not rational. They root in the syncretic world outlook behind which stands certain ontology.

The syncretic world outlook considers the being in the total universal unity organized according to the principle "All in All". In this ontology, diverse objects amalgamate not losing their individual differences. Similarity and even sameness arise among dissimilar things, and a power of every element enriches a power of all other within the limits of their differences. Syncretism is retention of binary oppositions in condition "to be this and other at the same time" [20].

To sum up the research, we should emphasize that modal relation and modal oneness are not explained by means semiotics and the theory of reference. Musical modi do not signify ethoses or cosmological phenomena but constitute the unity with them. The results of the study indicate the musical modi should be considered as elements of a musical ontology can be regarded in the context of the multidimensional syncretic modal ontology. The musical modi are the forms of cosmic and spiritual regularities. This approach allows explaining how the forms of sounding material can have the other dimension where they are phenomena of cosmological or ethical order.

\section{REFERENCES}

[1] Y. Moskva. "The main categories of the modality of the Gregorian chant", Muzykal'nayaakademiya, 2, 2007, p. 163.

[2] T.S.Bershadskaya. "Misunderstanding, becoming a tradition(Towards the problem: tonal modes - modal mades)", Muzykal'nayaakademiya, 1, 2008,pp.175-178.

[3] Th.Karp. "Rhythmic mode",Encyclopedia Britannica. URL: https://www.britannica.com/art/rhythmic-mode.

[4] A.A. Medova. "Modal logic and modal harmony: in the search of a scientific paradigm", Observatory of Culture, 2, 2013,pp. 10-18.

[5] A.A. Medova. "Musical modality as a type of thinking: the logic of the modal mode", Kul'turaiiskusstvo, 5, 2015, pp.565-574.

[6] The Analects of Confucius,book XIII, Frg. III.

[7] "The Republic of Plato", trans. with notes and an interpretive essay by Allan Bloom, Basic Books, 1991, p. 102.

[8] Cited by E. Gercman. Antique musical thinking,Leningrad: Muzyka, 1986,p. 55.

[9] N.L. Cherkasova. "The raga and its place in the Indian musical culture. Essays",Moscow, NTC Konservatoriya, 1993, pp. 18-19.

[10] W. Kaufmann. TheRagasofNorthIndia,London, 1968,p. 15.

[11] N.L. Cherkasova. "The raga and its place in the Indian musical culture. Essays",Moscow, NTC Konservatoriya,p. 18.

[12] A.Ortony, T. J. Turner."What's basic about basic emotions?”,Psychological review, Vol. 97, № 3,1990, p. 316.

[13] D. Zoltai. "Ethos and affect. The history of philosophical musical aesthetics from incipience to Hegel",Moscow,Progress, 1977,p. 39.

[14] Ibid. S. 43.

[15] CitedbyE.G.Meshcherina. "The musical culture of the medieval Rus",Moscow,Canon+; ROOIReabilitaciya, 2008,p. 162.
[16] E. Nazajkinskij. "The Logic of musical composition", Moscow,Muzyka, 1982,p. 243.

[17] S.Rao, W. van der Meer. "The construction, reconstruction, and deconstruction of shruti"/ J. Bor, F. Delvoye, J. Harvey, \& E. teNijenhuis, Hindustani music: thirteenth to twentieth centuries, New Delhi, Manohar, 2010, p. 691.

[18] D. Ramos, J.L.O.Bueno, E. Bigand. "Manipulating Greek musical modes and tempo affects perceived musical emotion in musicians and nonmusicians", Brazilian Journal of Medical and Biological Research,Vol. 44,Issue 2, 2011, pp. 165-172.

[19] Ibid. S. 168.

[20] R. Ascott. "Syncretic Reality: art, process, and potentiality", Drain magazine, Vol.2, № 2,2005, http://drainmag.com/index_nov.htm. 